and thorough evaluation by an ear, nose, and throat specialist is mandatory as surgery with radiotherapy cures some of these patients. ${ }^{14}$ Similarly, squamous tumours in the inguinal lymph nodes should prompt a careful search for perianal or genital primaries and treatment for these.

A small but important group of patients with responsive tumours has been identified by Hainsworth and colleagues. ${ }^{15}$ They report a $56 \%$ response rate (including $22 \%$ complete responses) to combination chemotherapy based on cisplatin in patients with poorly differentiated carcinoma or adenocarcinoma with one or more of the following features: age less than 50; tumours affecting primarily midline structures (the mediastinum and retroperitoneum), lungs, or lymph nodes; increased serum $\alpha$ fetoprotein or $\beta$ subunit of human chorionic gonadotrophin concentrations; clinical evidence of rapid tumour growth; and tumour very responsive to previous radiotherapy or chemotherapy. They reported that $13 \%$ of their patients were alive and free of disease five years after treatment. Young patients with disease mainly in lymph nodes seemed to have the best outcomes.

The same group also reported a $78 \%$ response rate and some long term survivors among patients with poorly differentiated carcinoma with neuroendocrine features on electron microscopy (dense core vesicles) or immunocytochemical staining. ${ }^{16}$ Small cell lung cancers and carcinoid tumours were excluded from this series. Unlike most adults with neuroendocrine diseases (for example, islet cell tumours and paragangliomas) the patients had rapidly progressive diseases. This entity is rare but important therapeutically.

For patients who fall into subgroups known to respond to treatment the argument for a trial of appropriate treatment is compelling. Specific drug treatment for the larger number with well differentiated or moderately differentiated adenocarcinoma in whom the primary site is not established is not mandatory and must be judged by the doctor for the individual patient in consultation with the patient and his or her family. For many, symptomatic care alone is indicated, but some patients should receive a more active approach. Although low, the expected response rate to chemotherapy is not substantially different from that which some patients and doctors consider to be acceptable for other cancers. The goal of treatment in these patients is palliation. With currently available antiemetics and other supportive measures a short trial of carefully monitored treatment can be worth while in selected patients with symptoms.

CHRISTOPHER BRADLEY Senior Registrar PETER SELBY Professor

Yorkshire Cancer Research Campaign Institute for Cancer Studies,

St James's University Hospital,

Leeds LS97TF

1 Altman E, Cadman E. An analysis of 1539 patients with cancer of unknown primary site. Cancer 1986;57:120-4.

2 Gatter KC, Alcock C, Heryet A, Mason DY. Clinical importance of analyzing malignant tumours of uncertain origin with immunohistochemical techniques. Lancet 1985;ii:1302-5.

3 Horning SJ, Carrier EK, Rouse RV, Warnke RA, Michie SA. Lymphomas presenting as histologically unclassified neoplasms: characteristics and response to treatment. $f$ Clin Oncol 1989;7:1281-7.

4 Kagan AR, Steckel RJ. The limited role of radiological imaging in patients with unknown tumour primary. Semin Oncol 1991;18:170-3.

5 McMillan JH, Levine E, Stephens RH. Computed tomography in the evaluation of metastatic adenocarcinoma from an unknown primary site A rotrospective study Radiology 1982;143:143-6. Kirsten F, Chi CH, Leary JA, Ng ABP, Hedley DW, Tattersall MHN. Metastatic adeno or

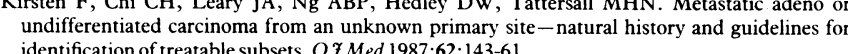

7 Le Chevalier T, Cvitkovic E, Caille P, Harvey J, Contesso G, Spielmann M, et al. Early metastatic cancer of unknown primary origin at presentation. A clinical study of 302 consecutive autopsied patients. Arch Intern Med 1988;148:2035-9.

8 Wadler S, Lembersky B, Atkins M, Kirkwood J, Petrelli N. Phase II trial of fluorouracil and recombinant interferon alfa-2a in patients with advanced colorectal carcinoma: an Eastern Cooperative Oncology Group study. F Clin Oncol 1991;9:1806-10.

9 Poon MA, O'Connell MJ, Moertel CG, Wieand HS, Cullinan SA, Everson LK, et al. Biochemical modulation of fluorouracil: evidence of significant improvement of survival and quality of life in patients with advanced colorectal carcinoma. F Clin Oncol 1989;7:1407-18.

10 Findlay M, Mansi JL, Ford HT, Nash AT, Cunningham D. Epirubicin, cisplatin and 5-fluorouracil (ECF) is highly effective in advanced gastric cancer. Eur f Cancer 1991;27(suppl 2):S71.

11 Sporn JR, Greenberg BR. Empiric chemotherapy in patients with carcinoma of unknown primary ite Am f Med 1990:88:49-55.

12 Milliken ST, Tattersall MHN, Woods RL, Coates AS, Levi JA, Fox RM, et al. Metastatic adenocarcinoma of unknown primary site. A randomised study of two combination chemotherapy adenocarcinoma of unknown primary site. A rando

13 Strnad CM, Grosh WW, Baxter J, Burnett LS, Jones HW, Greco FA, et al. Peritoneal carcinomatosis of unknown primary site in women. A distinctive subset of adenocarcinoma. Ann Intern Med $1989 \cdot 111 \cdot 213-7$

14 Lee DJ, Rostock RA, Harris A, Kashima H, Johns M. Clinical evaluation of patients with metastatic squamous carcinoma of the neck with occult primary tumor. South Med f 1986;79:979-83.

15 Greco FA, Vaughn WK, Hainsworth JD. Advanced poorly differentiated carcinoma of unknown primary site: recognition of a treatable syndrome. Ann Intern Med 1986;104:547-53.

16 Hainsworth JD, Johnson DH, Greco FA. Poorly differentiated neuroendocrine carcinoma of unknown primary site: a newly recognized clinicopathologic entity. Ann Intern Med 1988;109: $364-71$

\title{
Reconsidering compensation for medical accidents
}

\section{Concentrate on those with the severest disabilities, whatever the cause}

No fault compensation is in retreat. The victors in the British election, the Conservatives, were the one major party that did not propose a no fault system for compensating medical accidents. The New Zealanders, who run a no fault scheme that has attracted international admiration, have just revised their scheme in a way that is likely to destroy it. The limited but successful schemes operating in Sweden and Finland are increasingly recognised not really to be no fault schemes, as they incorporate many notions that are close to fault. And there is a feeling-strongly expressed at a conference on alternative systems for compensating the victims of medical accidents held in Oxford earlier this month - that it may be better to concentrate resources on those who are severely disabled regardless of the cause of their disablement.

Almost nobody at the conference had a good word to say about tort as a means of compensating those injured in medical accidents. It is slow, capricious, and hugely wasteful of resources. Jeffrey O'Connell, professor of law at the University of Virginia, described it as offering "a ticket to a prize fight in which the victim gets punched by both sides." The aim in reforming the tort system must be, said Professor O'Connell, to shift the resources now wasted on transaction costs, compensating non-economic loss (pain and suffering), and duplicating funds met from collateral sources into the pockets of those who are severely injured. Most systemsincluding many no fault schemes-overcompensate the mildly injured and undercompensate the seriously injured. Professor O'Connell warned, however, about being too ambitious when trying to reform existing systems. He quoted the American senator Daniel Moynihan, who said, "We live in a world of competing sorrows" and pointed out that not all of those sorrows can be compensated.

One of the most difficult problems with no fault schemes is to define those events that should be compensated. Professor O'Connell described the failure of a Virginian scheme that aimed at compensating those children injured in birth accidents: the definition drawn up by a multidisciplinary team proved so exclusive that there has never been a successful claim. The New Zealand scheme, said Margaret Vennell from 
the law faculty in Auckland, now includes a definition of medical misadventure that covers a couple of pages. Most of those at the conference thought that resorting to such complexity was a prelude to disintegration of the scheme.

The usual reason for resisting no fault schemes is their expected high cost together with the fact that the funds come from public expenditure. The New Zealand scheme has been a scapegoat for the collapse of the country's economy, and many North American and European economies are running up large budget deficits because governments are not containing public expenditure yet are unwilling to raise taxes. No fault compensation schemes are unlikely to flourish in such circumstances, and in Britain calculations from Paul Fenn of Oxford University suggest that the present tort system costs the NHS about $£ 60 \mathrm{~m}$ whereas a no fault scheme would cost between $£ 235 \mathrm{~m}$ and $£ 350 \mathrm{~m}$. NHS costs may well rise steeply and a no fault scheme would compensate many more people more efficiently than a tort scheme, but, with Britain heading for a disastrous budget deficit, funding for a scheme is unlikely to be forthcoming.

Another potential problem with no fault schemes is that they do not provide accountability. Yet this, says Arnold Simanowitz, the director of Action for the Victims of Medical Accidents, is what accident victims want most. Donald Harris, director of the Centre for Sociolegal Studies in Oxford, argued that it was impossible for one system to supply efficiently both compensation and accountability. Other systems like practice guidelines, audit, education and licensing, complaints procedures, and disciplining or retrain- ing of the incompetent are needed to maintain accountability. But economists at the meeting were bothered that replacing tort with a no fault system removed financial incentives for keeping up standards, and this anxiety has been important in the revision of the New Zealand scheme.

So if the tort system is hopeless and no fault schemes flawed, what options are there for compensating the injured? The best system may be a development of social security schemes for helping the severely disabled. Pauline Thompson, director of the Disablement Income Group, described how the costs of disablement have been grossly underestimated in Britain and how social security provision for disabled people is inadequate. But after the revision of the social security system in Britain in 1988 the government introduced the independent living fund for severely disabled people on low incomes, and the fund's expenditure has increased from $£ 5 \mathrm{~m}$ in the first year to about $£ 100 \mathrm{~m}$ in $1992-3$. This growth shows the scale of need-much of it, judging by regional variations in payout from the fund, still unmet - and most of those at the conference agreed that a scheme that got funds to such people and avoided arguments over causation was better than a scheme that allocated funds to particular categories of the disabled, some of whom had relatively minor injuries. Professor Harris suggested that if a no fault scheme for victims of medical accidents is ever introduced in Britain it should be reserved for those with high degrees of disablement that last for a long time.

Editor, $B M \mathcal{F}$

RICHARD SMITH

\section{Measuring case mix}

\section{Essential for managing resources; of less use for managing patients}

"The care you provide for your patients costs too much." "Your length of stay is longer than the regional average."

"The cost per patient is greater than it was last year, and we are going to overspend."

Such statements are common in the fight to balance budgets, and doctors find them difficult to respond to. How may we ensure that the comparisons are fair? Are different kinds of patients being treated? Are the patients in our unit more likely to require expensive care because they have more complicated illnesses? If they are then some of the difference in costs may be due to the kinds of patients rather than to differences in the efficiency of care. The problem is how to determine the proportion that is due to the variation in clinical case mix.

In principle, the solution should be easy. The population of patients should be broken down into a few groups consuming similar amounts of health care ("isoresource" groups). Comparison could then be made between groups after they had been standardised to take account of the differing age mixes of the populations (in much the same way as standardised mortality ratios are calculated).

In practice, constructing satisfactory groups is not that simple, and teams of researchers have been working on these problems for at least the past 20 years. A history of their endeavours in the United Kingdom has recently been published. ${ }^{\prime}$

Early developments in this topic and much of the subsequent research have come from the United States. Among the early pioneers a team at Yale, led by Bob Fetter and John Thompson, developed a grouping system known as diagnosis related groups (DRGs). ${ }^{2}$ The 467 groups were based on diagnoses, procedures, and other information available in the computerised hospital discharge record. The system was therefore cheap and simple to apply and performed reasonably well in producing groups that consumed similar amounts of resources. For these reasons it was adopted by the Medicare administration as a pricing schedule for reimbursing hospitals and has since been the focus of vigorous debate.

Until the introduction of resource management in $1986^{3}$ interest in the use of case mix groupings in Britain was largely confined to groups of researchers who wanted either to explain variations in lengths of stay between hospitals ${ }^{4}$ or to examine the effect of introducing changes in management on the mix of cases treated. ${ }^{5}$ The central philosophy of resource management was the devolution of responsibility for the budget to clinical directors. This required the development of directorate budgets and monitoring expenditure against those budgets. Directors rapidly realised that to develop budgets that would meet their clinical work plans they needed information on the resources each patient would be likely to use. Equally, when monitoring expenditure directors needed to know the expected costs of the patient's treatment. Only then could the reasons for variances in budgets be determined. All this implied a grouping of patients into "similar resource use" groups. The feasibility of using diagnosis related groups for this purpose was evaluated and confirmed in the pilot sites. As doctors began to understand diagnosis related groups and the properties of the groups were examined in more detail, however, it became clear that in England some groups contained mixtures of patients that were not similar 